\title{
Article
}

\section{A comprehensive community-based prevalence study on noctu- ria in Hong Kong male adults}

\author{
John Wai-Man Yuen 1, , Ivy Yuen-Ping Wong 1, Peter Ka-Fung Chiu ${ }^{2}$, Jeremy Yuen-Chun Teoh ${ }^{2}$, Chi-Kwok Chan ${ }^{2}$, \\ Chi-Hang Yee ${ }^{2}$ and Chi-Fai $\mathrm{Ng}^{2}$ \\ 1 School of Nursing, The Hong Kong Polytechnic University, Hung Hom, Kowloon, Hong Kong; \\ john.yuen@polyu.edu.hk; ivy.y.p.wong@polyu.edu.hk \\ 2 S.H. Ho Urology Centre, Department of Surgery, The Chinese University of Hong Kong, Shatin, Hong \\ Kong; peterchiu@surgery.cuhk.edu.hk; jeremyteoh@surgery.cuhk.edu.hk; chanck@surgery.cuhk.edu.hk; \\ yeechihang@surgery.cuhk.edu.hk; ngcf@surgery.cuhk.edu.hk \\ * Correspondence: john.yuen@poly.edu.hk; +852-2766-4130:
}

\begin{abstract}
Background: Most prevalence surveys on nocturia have focused on older populations. This study aimed to measure the nocturia prevalence across the full spectrum of male adults living in Hong Kong, where severity and associated quality-of-life (QoL) were also explored. Methods: A cross-sectional population-based survey was conducted in men aged 18 or above using the ICIQNQoL Questionnaire. Results: With 1,239 respondents at age ranged 18-99, the overall nocturia prevalence were found to be $63.0 \%$ (ranged $41.6-84.6 \%$ at different age groups) and $31.2 \%$ (ranged $13.0-56.3 \%$ at different age groups), for $\geq 1$ and $\geq 2$ bedtime voiding episodes, respectively. The chance of nocturia was dramatically increased at age 60 or above while both prevalence and voiding frequency were increased with advancing age. About $83 \%$ of the nocturia men experienced 1-2 voiding episodes per night, but many of them had self-rated their QoL poor or very poor and indicated moderate-to-high bothersome. Younger men at age 18-39 were found to have high prevalence as $41.6 \%$ and almost $30 \%$ of them rated poor or very poor QoL. Conclusions: Nocturia was not only affecting the older populations but also caused significant bothersome and negative impacts on QoL in younger males.
\end{abstract}

Keywords: Nocturia; Quality of life; Lower urinary tract symptoms, Male adults, NQoL, Urinary frequency, Bedtime urination.

\section{Introduction}

Many senior males are living with suboptimal sleep cycle and Quality of Life (QoL) that could be caused by the problem of nocturia. Nocturia is one of the most popular lower urinary tract symptoms (LUTS), which describes the condition of waking at night to void while each void is preceded and followed by sleep [1]. Individuals with nocturia were suffering from sleep disturbance, but also commonly experiencing decreased levels of well-being, general health, vitality and essential biological rhythms [2-3]. Sleep quality was identified as a major mediator for several QoL domains impacted by the nocturia [4]. The association between ageing and nocturia could be at least partially explained by their comorbidity with age-related conditions ranging from urological illnesses to metabolic and neurological disorders; however, increasing trends have also observed in younger men [5-8]. Medications and lifestyle habits were identified as additional causes of nocturia affecting all age groups [8-10]. Nonetheless, the multifactorial 
nature of nocturia was shown to impact QoL negatively that has drawn much public health attention.

Numerous studies have reported prevalence of nocturia as both $\geq 1$ and $\geq 2$ voids per night, because the urology field believed clinical significance to affect energy metabolism and productivity is sought to at least two bedtime wakes [1112]. Bosch \& Wesis [13] had gathered all English studies from 1990 to 2009 and reported prevalence rates across geographical locations, at $11-35 \%$ versus $2-17 \%$ among men aged $20-40$ while at $69-93 \%$ verses $28-62 \%$ among older men aged $>70$, for $\geq 1$ and $\geq 2$ voids, respectively. In Asia, LUTS affected $60 \%$ of men $\geq 40$ years and with $38 \%$ were nocturia, which was regarded as the most prominent and bothersome urinary storage symptom [14]. In a study conducted among five Asian countries, older males aged 50-80 living in Hong Kong has ranked the second highest prevalent population for moderate-to-severe LUTS at $48 \%$ just following the 59\% prevalence of Philippines [15]. In Hong Kong, nocturia was identified as the most prevalent LUTS affecting two-third of men $\geq 40$ years who have reported two or more voids per night [16]. Recently, local prevalence of nocturia were reported exceptionally high as $93 \%$ and $77 \%$ for $\geq 1$ and $\geq 2$ voids per night, respectively in male patients surveyed in multiple public urology clinics, and many had self-reported 'some" or "a lot of" bothersome feeling was caused by nocturia [17]. Whereas, another telephone-based survey has revealed much lower prevalence rates among men aged $>40$ in the community at $63 \%$ and $32 \%$ for $\geq 1$ and $\geq 2$ voids per night, respectively [18]. However, the age-specific prevalence rates were selectively reported in men at older ages in 2005, as 64\% for age $51-60$ and $81 \%$ for age over 70 , for having $\geq 1$ void per night [19]. Furthermore, in a small-scale local interview study, $60 \%$ of newly retired men had reported their sleep were disturbed by nocturia in the past six months, and more than half of them had not taken any actions for solving this problem but felt distressed [20]. Yet, the previous prevalence studies were mainly focused on older populations of selected age groups from clinical settings or through phone interviews [18-19]. Therefore, the current study was conducted to clarify the population-based prevalence of nocturia and measure its impacts on health-rleated QoL using the Nocturia Quality of Life module of the International Consultation on Incontinence Modular Questionnaire (ICIQ-NQoL), in adult males living in Hong Kong.

\section{Materials and Methods}

\section{Study design \& subject recruitment}

This cross-sectional study adopted a street-intercept survey design to measure the prevalence of nocturia and its health-related QoL perceived by adult males living in Hong Kong, using the Cantonese version of the ICIQ-NQoL. The target population of this study was adult males who were of Chinese ethnicity at age $\geq 18$ and staying in Hong Kong as their usual residential place for $>180$ days prior to the survey. Foreign domestic helpers and individuals who could not 
understand and speak Cantonese were excluded. According to the Hong Kong census [20], in the middle of 2016, there were 2,846,845 adult males living in the city, with $92.0 \%$ belonging to the Chinese ethnicity and $88.9 \%$ having Cantonese as the usual language who were eligible to participate in this study. During July to August 2016, data collectors were allocated to visit different public spots (mainly parks, recreation facilities, and transportation hubs) of residential areas in 13 districts for sampling. The accessibility covered $78.8 \%$ of the entire targeted population, as the commercial, industrial and border districts, rural areas and remote islands were excluded in this study [20]. Each data collector spent 3$4 \mathrm{~h}$ at each allocated spot at each visit, and 5-6 questionnaires were completed on average per hour. In case of non-response, the next individual would be approached, and call-backs were not implemented. The nature and purpose of the study was verbally explained after confirming the eligibility, then the individual was invited to complete the anonymous questionnaire. Implied consent of participation was assumed by completing the survey. Ethical approval has been obtained from the Human Ethical Sub-committee of the Hong Kong Polytechnic University. During the sampling period, a total of 3,672 male pedestrians was approached with 1,239 eligible participants (response rate $=33.7 \%$ ) having completed the questionnaire.

\section{The instruments}

The ICIQ-NQoL questionnaire was developed and validated for measuring the impacts of nocturia on QoL [21]. The Cantonese version was translated and back-translated from the original English version obtained from ICIQ webpage (http://www.iciq.net/ICIQ.nqolmodulepage.html). The validation protocol suggested by the ICIQ group was followed. Bilingual native speakers of Hong Kong, being a Cantonese speaker and English speaker were invited to conduct the initial and back translation, respectively. The back translated version was reviewed by the ICIQ group, and appropriate adjustment was made as recommended. Finally, the translation was accepted following the completion of the pre-test with 18 adult males who have completed the translated questionnaire and a set of interviewer questions provided by the ICIQ group. Those 18 adult males were recruited from the Urology Clinic of the Prince of Wales Hospital, and the onemonth test-retest reliability for the Cantonese ICIQ-NqoL was determined as good with an overall test-retest coefficient of 0.79 while 0.69 for factor- 1 and 0.87 for factor-2, which were also acceptable. The Cronbach's alpha reliability based on the current sampled population was found to be highly reliable with $\alpha=0.90,0.87$ and 0.85 for the overall, factor 1 and factor 2 subscales, respectively.

Constructs of the original ICIQ-NQoL remain unchanged, which consists of 13 items to measure the overall and two factor scores. The scoring scheme was based on the 5-point Likert scale (from 0 to 4) of 'frequency' on having the feeling described in each item in the past two weeks. The overall NQoL score ranged 
0-52 was calculated by summing up the scores of all 13 items, with greater value indicating higher impact on QoL. Whilst the factor scores of the subscales were calculated by summing up the scores of corresponding items, i.e. 6 items (No. 1, $2,3,4,5,7)$ in factor- 1 score for measuring the impact on 'sleep/energy' ranged $0-24$; and 7 items (No. 6, 7, 8, 9, 10, 11,12) in factor-2 score for measuring the impact on bother/concern ranged 0-28 [16]. The item 7 asked 'difficult to get enough sleep at night' was overlapping in both subscales.

Table 1. Characteristics of the studied populations, and comparisons between individuals with and without nocturia.

\begin{tabular}{|c|c|c|c|c|}
\hline \multirow[t]{2}{*}{ Variables } & $\begin{array}{c}\text { Total } \\
\mathrm{N}=1239\end{array}$ & $\begin{array}{c}\begin{array}{c}\text { Non-nocturia } \\
\mathrm{N}=\mathbf{4 5 8}\end{array} \\
\end{array}$ & $\begin{array}{c}\text { Nocturia } \\
\mathrm{N}=781 \\
\end{array}$ & \multirow[t]{2}{*}{$\begin{array}{c}\chi^{2} \\
\text { p-value }\end{array}$} \\
\hline & \multicolumn{3}{|c|}{ Number (Percentage) } & \\
\hline \multicolumn{5}{|l|}{ Demographics } \\
\hline Mean age \pm SD, years & $56.57 \pm 15.22$ & $49.83 \pm 14.84$ & $60.52 \pm 14.01$ & $<0.001^{\#}$ \\
\hline Married/cohabited & $822(66.3)$ & $306(66.8)$ & $516(66.1)$ & 0.789 \\
\hline Education $<$ college & $750(60.5)$ & $217(47.4)$ & $533(68.2)$ & $<0.001$ \\
\hline Current smoker & $296(23.9)$ & $91(19.9)$ & $205(26.2)$ & $<0.001$ \\
\hline Frequent drinker & $312(25.2)$ & $107(23.4)$ & $205(26.2)$ & 0.489 \\
\hline \multicolumn{5}{|l|}{ Waketime Urination } \\
\hline Every hour & $56(4.5)$ & $13(2.8)$ & $43(5.5)$ & $<0.001$ \\
\hline Every 2 hours & $330(26.6)$ & $81(17.7)$ & $249(31.9)$ & \\
\hline Every 3 hours & $485(39.1)$ & $173(37.8)$ & $312(40.0)$ & \\
\hline$\geq$ Every 4 hours & $368(29.7)$ & $191(41.7)$ & $177(22.7)$ & \\
\hline Bothersome (0-10), mean \pm SD & $1.67 \pm 2.20$ & $0.93 \pm 1.53$ & $1.78 \pm 2.27$ & $<0.001^{\#}$ \\
\hline \multicolumn{5}{|l|}{ Health \& Illnesses } \\
\hline $\mathrm{DM}$ & $181(14.6)$ & $34(7.4)$ & $147(18.8)$ & $<0.001$ \\
\hline $\mathrm{Hx}$ & $448(36.2)$ & $98(21.4)$ & $350(44.8)$ & $<0.001$ \\
\hline $\mathrm{DM}+\mathrm{Hx}$ & $153(12.3)$ & $30(6.6)$ & $123(15.7)$ & $<0.001$ \\
\hline $\mathrm{BPH}$ & $96(7.8)$ & $9(2.0)$ & $87(11.1)$ & $<0.001$ \\
\hline Prostate cancer & $5(0.4)$ & $0(0)$ & $5(0.6)$ & 0.086 \\
\hline Taking BPH medication & $65(5.3)$ & $7(1.5)$ & $58(7.4)$ & $<0.001$ \\
\hline Health state $(0-100)$, mean \pm SD & $72.85 \pm 12.57$ & $76.79 \pm 11.41$ & $70.17 \pm 12.64$ & $<0.001^{\#}$ \\
\hline
\end{tabular}

\#Student's t-test.

\section{Date processing and statistical analysis}

For studying the impact on QoL and its characteristics, the definition of International Continence Society for nocturia was adopted, and therefore, the nocturia population of this study is defined as those who had $\geq 1$ void per night. Data collected from the survey were entered and analyzed using the SPSS version 25.0 (IBM, NY, USA) and the Prism version 8.0 (GraphPad, CA, USA). Descriptive statistics (frequency and percentages) were used to describe the demographic data, medical conditions, urination frequency, and prevalence of nocturia and bothersome. Chi-squared test, students' t-test, and one-way ANOVA were used 
to assess the significant differences of nominal and continuous variables between two groups.

\section{Results}

\subsection{Prevalence and characteristics of nocturia}

A total of 1,239 men were recruited from 3,672 male pedestrians who had been approached (with a response rate of 33.7\%) in multiple districts of Hong Kong. As shown in Table 1, the studied population reported a mean age of 56.7 \pm 15.2 (ranged 18-99), two-thirds were married, around one-fourths were current smokers or frequent drinkers, and $60.0 \%$ received education below college level. There were 781 out of the population reported at least one bedtime void per night that estimated an overall prevalence rate of $63 \%$, of which was reduced to $31.2 \%$ when only those experiencing two voids per nights were counted. When compared with those without nocturia, the nocturia group perceived a poorer health status $(70.2 \pm 12.6$ versus $76.8 \pm 11.4 ; \mathrm{p}<0.001)$ with more encounters of various health conditions including diabetes mellitus (DM), hypertension (Hx), DM$\mathrm{Hx}$ comorbidity, benign prostatic hyperplasia (BPH) and use of medications for treating BPH (Table 1).

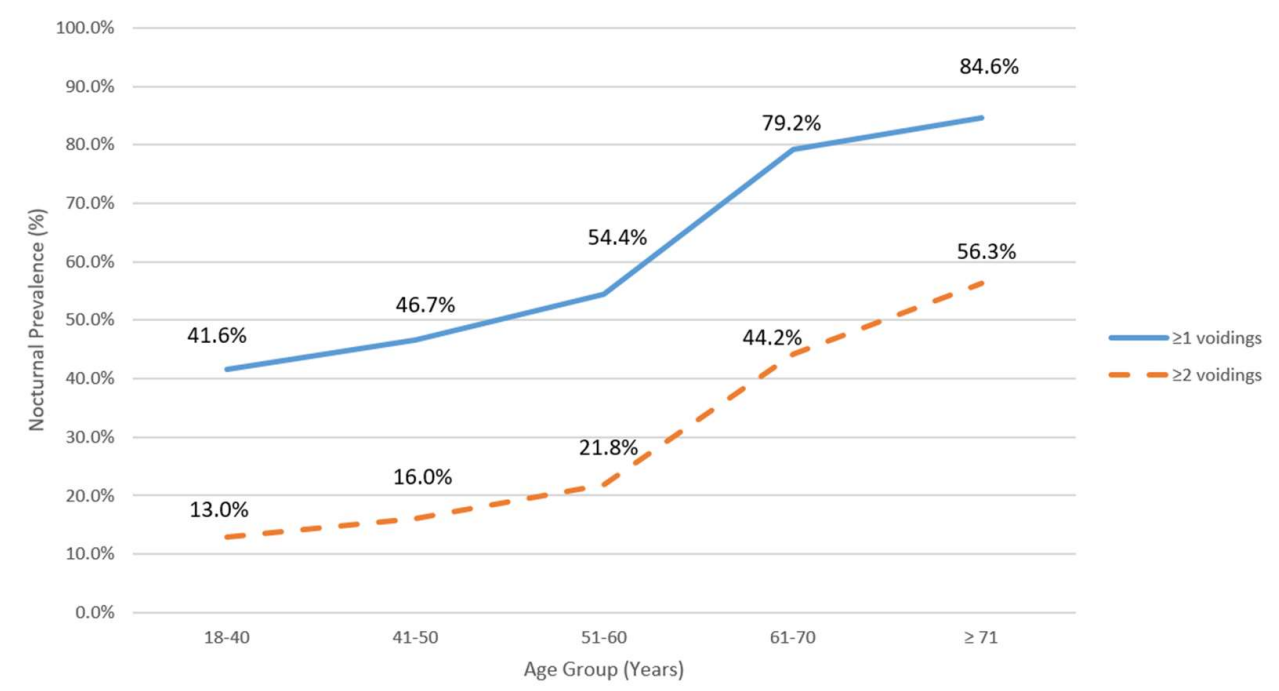

Figure 1. Prevalence of nocturia in different age groups.

In the studied population, the prevalence of nocturia was increased with advancing age and observed in exactly the same trends between $\geq 1$ and $\geq 2$ voiding frequencies (Figure 1). The upwards trends were segmented into two linear curves by age 60 , with relatively steady gradual increases (41.6-54.4\% and 13.0$21.8 \%$ ) from age 18 to 60 , and then followed by a rocketing increase to $79.2 \%$ and $44.2 \%$ at age $61-70$ and to $84.6 \%$ and $56.3 \%$ at age $\geq 71$, with voiding frequency $\geq 1$ and $\geq 2$, respectively (Figure 1 ). In particular for younger adult males 
at age 40 or below, high prevalence were reported as $42 \%$ for $\geq 1$ void and $13 \%$ for $\geq 2$ voids (Figure 1).

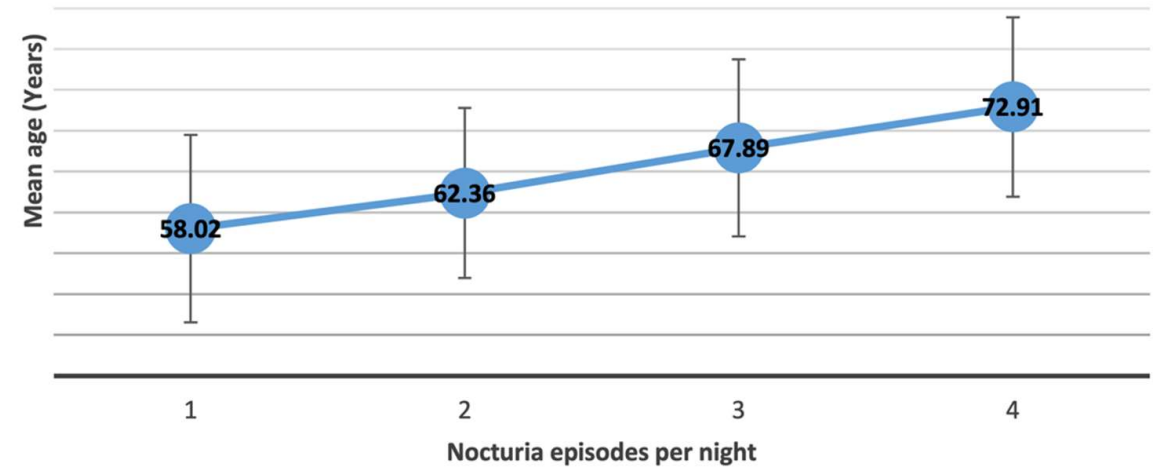

Figure 2. The linear relationship between age and nocturia episodes.

The number of nocturia episodes was in clear linear correlation with the age (Figure 2). Despite the vast majority of nocturia population (83.0\%) was reported with experience of $1-2$ voiding episodes per night, as a sum of $50.5 \%$ and $32.5 \%$ for voiding once and twice, respectively (Figure 3a), the remaining 17\% with 3-4 voiding frequency or more were remarkably older at age $(69.9 \pm 10.1$ versus $58.6 \pm 13.9 ; \mathrm{p}<0.001)$. Figure $3 \mathrm{~b}$ indicated that voiding frequency $\geq 3$ was rarely reported by individual below age 40 at around $1.5 \%$, but the prevalence was elevated dramatically to $4.6-9.9 \%$ at age range of $41-60$ and $19.4-32.1 \%$ at age $>60$ (Figure 3c-e). Specifically for those at age $\geq 71$, high prevalence rates were found as $20.1 \%$ and $12.0 \%$ for 3 and 4 voiding frequencies, respectively (Figure $3 \mathrm{f}$ ).

\subsection{Nocturia-related QoL and bothersome}

The ICIQ-NQoL scale was used to measure the negative impact of nocturia on QoL. Overall, $14.9 \%$ of the nocturia males have rated their QoL level poor/very poor while $44.0 \%$ and $32.8 \%$ of them were having 1 and 2 voids per night, respectively (Table 2). This indicated that QoL of individuals could also be significantly affected by just 1-2 nocturia frequencies, despite almost $30 \%$ of individuals experiencing $\geq 4$ voids per night were reported poor/very poor QoL rating (Table 2). 




(a)

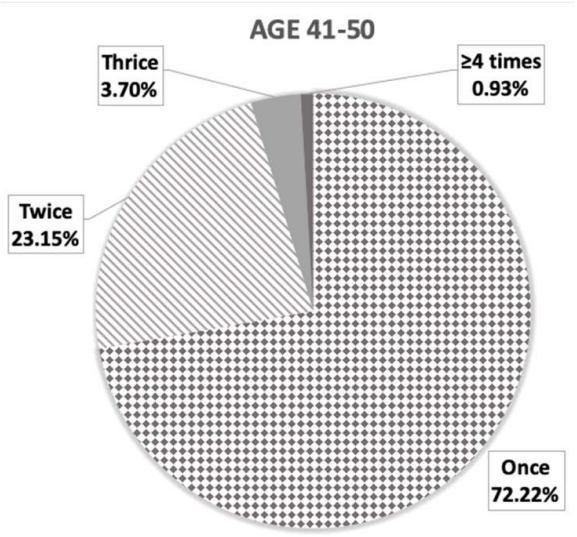

(c)

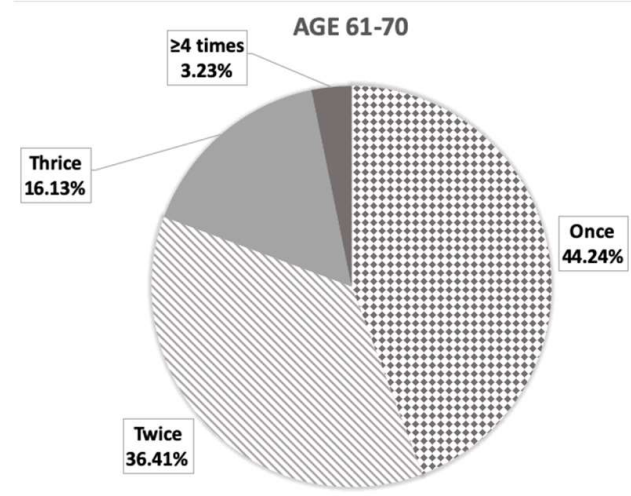

(e)

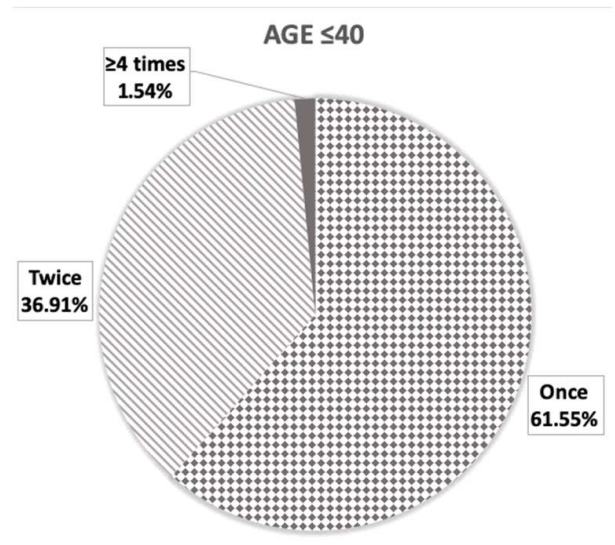

(b)

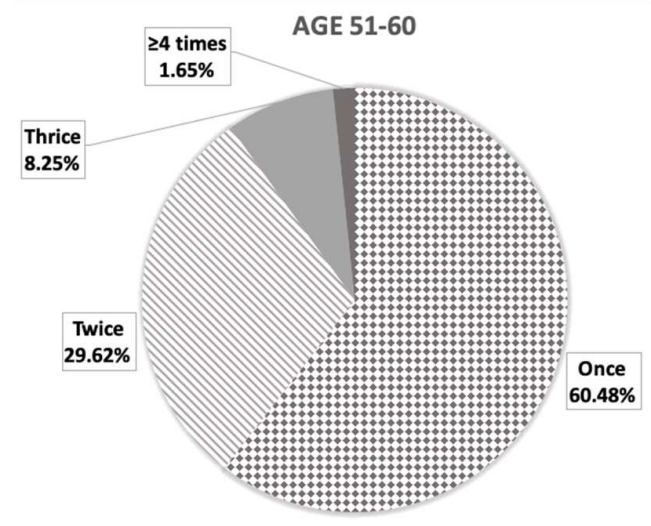

(d)

AGE $\geq 71$

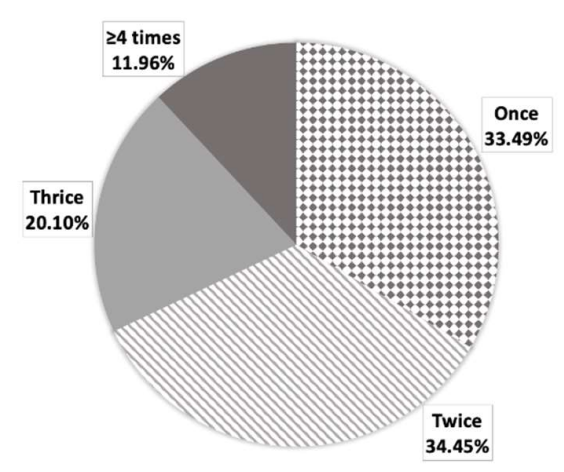

(f)

Figure 3. Distribution of nocturia episodes in: (a) the overall studied nocturia population, which was divided into different age groups at: (b) 18-40 years; (c) 41-50 years; (d) 51-60 years; (e) 61-70 years; and (f) $\geq 71$ years.

When comparing between individuals with nocturia who were above and below age 40, the percentages of respondents rated their overall QOL poor or very poor were $14.9 \%$ versus $29.2 \%$, respectively. The studied nocturia population reported a mean self-rated NQoL score at $14.1 \pm 9.1$ out of the total score of 52, with the sleep/energy (factor 1) and bother/concern (factor 2) scores were 6.0 \pm 4.8 and $7.7 \pm 5.4$, respectively. The overall $\mathrm{NQoL}$ and its factor scores were shown to 
follow the same trends with the voiding frequency (Figure 4a) and age of the respondents (Figure $4 \mathrm{~b}$ ). Clear increasing trends were observed with the voiding frequency as a severity indicator (Figure 4a). On the other hand, increasing trends were observed with age above 40; however, the overall and factor scores of the age group at 18-40 were higher than those measured in the age group of 41-50 and at equivalent level with the 51-60 age group (Figure $4 \mathrm{~b}$ ). The item 'difficult to get enough sleep at night' was identified as the commonest QoL aspect that has factored both the 'sleep/energy' (factor 1) and 'bother/concern' (factor 2). For factor 1, difficulty in getting enough sleep at night has caused individuals to nap during daytime, which was shown to affect at least one-fourths of individuals experiencing $\geq 1$ void while the highest with over $60.0 \%$ of those experiencing 3 voids. The other two items 'difficult to concentrate the next day' and 'feel no energy the next day' were predominantly affecting nocturia male individuals experiencing $\geq 2$ bedtime voids. For factor 2 , 'concerned that must get up in the middle of the night to urinate' was the most frequent single aspect particularly concerned by more than half of individuals having $\geq 3$ voids. Whilst another item 'pay more attention of when and how much to drink' has also been concerns of $30-50 \%$ of the nocturia males, whereas the observed trend was in reverse relationship with increasing voiding frequency.

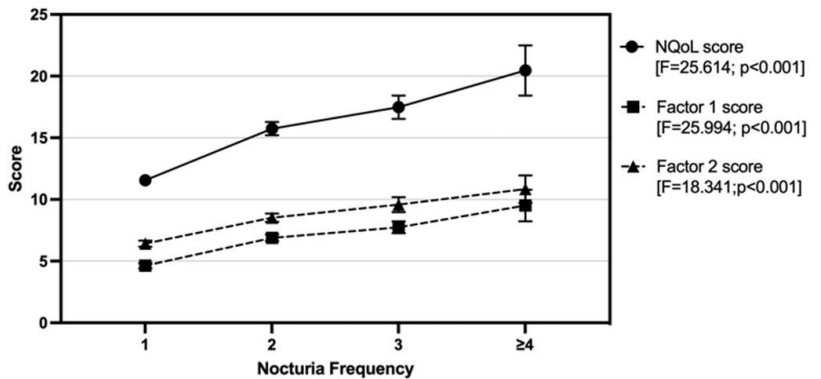

(a)

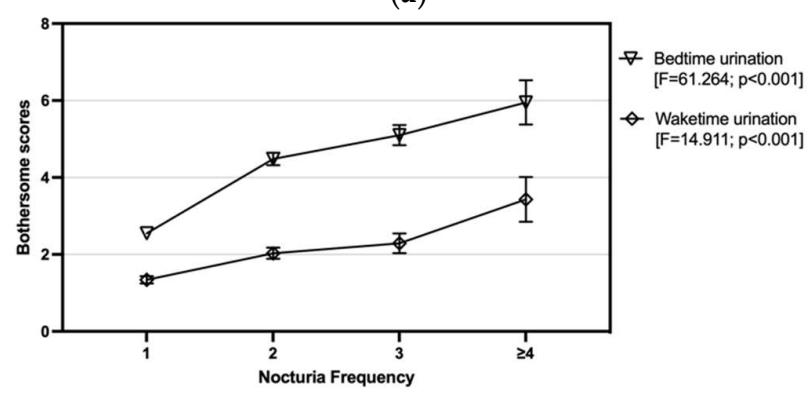

(c)



(b)

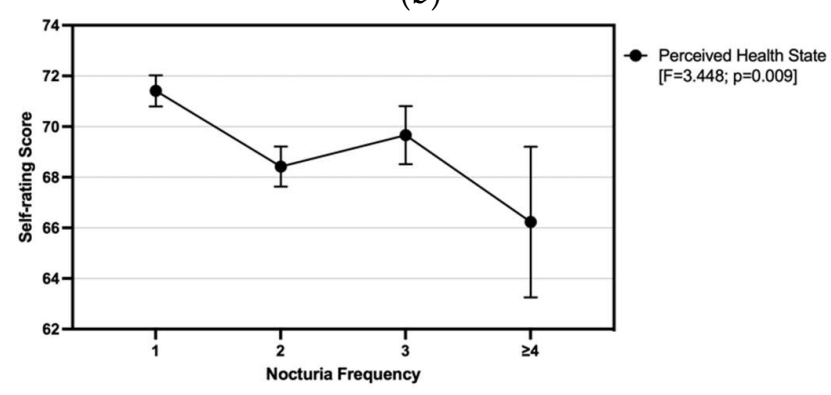

(d)

Figure 4. Nocturia-related QoL, bothersome caused by nocturia, and health state perceived by the individuals with nocturia, are presented as the trends of: (a) NQoL score and factor scores against the increasing nocturia frequency, and (b) against the advancing age groups, and (c) the bothersome score and (d) the health state score against the increasing nocturia frequency.

Approximately $40 \%$ of nocturia men have rated a score of 5 or above to indicate moderate-to-high bothersome levels caused by the bedtime urination, despite 
the mean score of the whole population was low as $3.7 \pm 2.7$ out of 10 . Consistent with the NQoL, the bothersome level was also elevated with the bedtime voiding frequency, whereas the bothersome score was peaked at 6.0 among those experiencing $\geq 4$ voids per night (Figure $4 \mathrm{c}$ ). Besides, many nocturia males were also bothered by their waketime urination frequency. As compared with the non-nocturia group, waketime urination in every 1-2 hours were about $20 \%$ more prevalent among nocturia males who also reported a significantly higher $(\mathrm{p}<0.001)$ bothersome score (Table 1). Nonetheless, as shown in Figure 2a, the bothersome scores of both bedtime and waketime urinations have followed similar upward trends with increasing nocturia frequency. Furthermore, the voiding frequency and health status of nocturia males were in a negative correlation relationship, where the health status score was decreased from the highest of $71.4 \pm 12.1$ for those experiencing 1 void to the lowest of $66.2 \pm 18.1$ for $\geq 4$ voids (Figure $4 \mathrm{~d}$ ).

Table 2. Chi-squared comparison of individual items of the NQoL scale between different nocturia frequency groups.

\begin{tabular}{|c|c|c|c|c|c|}
\hline \multirow[t]{4}{*}{ NQoL items } & \multicolumn{4}{|c|}{ Nocturia Frequency } & \multirow{4}{*}{$\begin{array}{c}\chi^{2} \\
\text { p-value }\end{array}$} \\
\hline & 1 time & 2 times & 3 times & $\geq 4$ times & \\
\hline & $\mathbf{N}=391$ & $N=254$ & $\mathrm{~N}=96$ & $\mathbf{N}=\mathbf{3 7}$ & \\
\hline & \multicolumn{4}{|c|}{ Number (Percentage) $)^{\#}$} & \\
\hline Rated the overall QoL poor/very poor & $51(13.0)$ & $38(15.0)$ & $16(16.7)$ & $11(29.7)$ & $<0.001$ \\
\hline \multicolumn{6}{|l|}{ Factor 1 (Sleep/Energy) } \\
\hline Difficult to concentrate the next day & $50(12.8)$ & $81(31.9)$ & $33(34.4)$ & $14(37.8)$ & $<0.001$ \\
\hline Feel no energy the next day & $73(18.7)$ & $103(40.6)$ & $51(53.1)$ & $18(48.7)$ & $<0.001$ \\
\hline Required to nap at day time & $92(23.5)$ & $124(48.8)$ & $59(61.5)$ & $17(46.0)$ & $<0.001$ \\
\hline Lowered next day's productivity & $41(10.5)$ & $53(20.9)$ & $19(19.8)$ & $11(29.7)$ & $<0.001$ \\
\hline Participate less in favorite activities & $42(10.7)$ & $37(14.6)$ & $22(22.9)$ & $14(37.8)$ & $<0.001$ \\
\hline Difficult to get enough sleep at night ${ }^{\wedge}$ & $121(31.0)$ & $123(48.4)$ & $61(63.5)$ & $19(51.4)$ & $<0.001$ \\
\hline \multicolumn{6}{|l|}{ Factor 2 (Bother/Concern) } \\
\hline Pay more attention of when and how much to drink & $168(43.0)$ & $117(46.1)$ & $37(38.5)$ & $12(32.4)$ & 0.012 \\
\hline Difficult to get enough sleep at night ${ }^{\wedge}$ & $121(31.0)$ & $123(48.4)$ & $61(63.5)$ & $19(51.4)$ & $<0.001$ \\
\hline $\begin{array}{l}\text { Worried disturbing others in the house because of having to get up } \\
\text { in the middle of night to urinate }\end{array}$ & $81(20.7)$ & $75(29.5)$ & $28(29.2)$ & $16(43.2)$ & 0.007 \\
\hline Concerned that must get up in the middle of the night to urinate & $85(21.7)$ & $99(39.0)$ & $55(57.3)$ & $20(54.1)$ & $<0.001$ \\
\hline Worried that the condition of night urination will get worse & $73(18.7)$ & $81(31.9)$ & $38(39.6)$ & $21(56.8)$ & $<0.001$ \\
\hline $\begin{array}{l}\text { Worried that there is no effective treatment for the condition of } \\
\text { night urination }\end{array}$ & $59(15.1)$ & $73(28.7)$ & $37(38.5)$ & $17(46.0)$ & $<0.001$ \\
\hline
\end{tabular}

"Participants who have rated some of night', 'most of the night' or 'every night' by participants ${ }^{\wedge}$ Item repeated in both factor subscales.

\section{Discussion}

The present comprehensive prevalence study estimated that $63 \%$ of Hong Kong male adults were living with nocturia, whereas its occurrence was clearly 
advancing with age affecting anywhere between $42 \%-85 \%$ from individuals of different age groups. To our best knowledge, this is also the first study reporting age-specific prevalence across the whole age spectrum of male adults ranging 1899 years and in accordance with the voiding episodes. Results of the ICIQ-NQoL measurement revealed that the QoL of men experiencing nocturia was affected at low-to-moderate levels that caused significant bothersome levels.

First of all, the current prevalence results were consistent with the report of a recent telephone-based survey conducted in Hong Kong [18]. These communitybased prevalence levels were remarkedly lower than those reported in the local clinical settings [17]. Comparing with other Asian and Western countries [2326], Hong Kong was shown to be at relatively high nocturia prevalence. It is agreed with the report amongst five Asian countries that Hong Kong was known to be the highest prevalent place for LUTS, where nocturia was dominated among elderly males [27]. Such high prevalence may be at least partially explained by the ageing population and stressful living environment emersed in the city. Results herein also suggested that the chance of nocturia was dramatically increased at ages after 60 , which was in line with the age-dependent nature of nocturia [26]. In general, accumulating evidence [6] has suggested the associations of nocturia with numerous age-related illnesses that were also identified in the current nocturia population. Besides ageing and related health conditions, two demographic factors were particularly shown to be strongly associated with nocturia. One was the smoking habits that its associated risk for nocturia has been reported in the Chinese male population [26]. Whilst the lower educational level received by the nocturia males, as reported in this study is believed to be identified the first time associating with the nocturia occurrence. A possible postulation could be that the lower social class commonly less educated may have longer working hours and less able to have urination during work, so to have a tendency for drinking less in the daytime but more after work (to refill) and late dinner, which resulting in nocturia. Furthermore, the present findings also revealed a relatively higher age-matched prevalence for $\geq 1$ void in younger men under 40 year-old, as compared with the $35 \%$ reported in the large European Prospective Investigation into Cancer and Nutrition (EPIC) cohort study conducted in major western countries [23]. Kalejaiye et al. [27] discussed the possible causes of LUTS and storage symptoms with predominance of nocturia. In relation to this, another research team [28] had invetsigated the urodynamic functions in 308 young men experiencing non-prostatic related LUTS and found that $80 \%$ of them were presented with storage symptoms. Pathologically, it was well established that nocturia could be caused by the decreased bladder storage capacity or increased urine output during sleep [6-7,9]. The former signifies the nocturia in younger individuals while the later predominantly occurring as nocturia polyuria (NP) in older adults as characterized by an increased proportion of the 24-hour urine output at night $[7,29]$. The age-related voiding frequency could be more accurately determined by the interaction between the rate of urinary output and 
the reservoir capacity of the low urinary tract [6], which was impossible to be detemrined in the current community-based survey conducted in streets. However, the etiologies of nocturia and especially for younger male populations required further investigations.

Recent research has paid more attentions to how QoL is impacted by nocturia. In the studied population, the NQoL scores measured by the ICIQ-NQOL scale, bothersome scores caused by bedtime urination and perceived health status scores were all correlated with the bedtime voiding frequency. The single item 'difficult to get enough sleep at night' was identified as the most frequently responded by the participants with nocturia, which was commonly factored into 'sleep/energy' and 'bother/concern' subscales. This was consistent with the notion of numerous studies that nocturia causes sleep disturbance and subsequently affecting daytime activities, productivity and social activities [10-11, 30]. Individuals who need to wake for urination at night were commonly suffering from certain degrees of sleep disturbance, which resulted in decreased levels of wellbeing, health, vitality and essential biological rhythms [23]. Nocturia was known to affect QoL both physcially and mentally, especially it was associated with increased incidence of depression [31]. In accordance with the current and previous studies, there was no doubt the negative impacts of nocturia on QoL were dependent on the advancing age and increasing frequency of bedtime voiding, as also identified in present study. Many urologists argued that at least twice bedtime voids per night should be considered as clinically significant to affect energy metabolism and productivity [11-12]. Evidence has suggested that energy and productivity of any individuals could be substantially influenced if nocturia occurs at twice or more voiding episodes per night [12]. On the contrary, this current study revealed that many of the respondents experiencing even a single bedtime void had self-rated a poor or very poor QOL with significant bothersome levels caused by nocturia, especially for those younger men who were under 40 of age. Given the fact that a vast majority of individuals were experiencing bedtime voiding limited at 1-2 episodes per night while voiding episodes per night $\geq 3$ were predominantly observed at the age above 60 , nocturia was shown to affect the QoL of all adult male ages regardless of the urination frequency. More investigations are needed to understand more in-depth on how men's QoL and other health-related parameters are influenced by nocturia, especially for those younger at age.

\section{Conclusions}

Nocturia was prevalent in two-thirds of male adults living in Hong Kong. Although both prevalence and voiding frequency were increased with advancing age, it bothered all ages by causing sleep disturbances. Despite the chance of nocturia was shown to be dramatically increased at 
age 60 or above, high prevalence was observed in younger men who also reported poor QoL. In conclusion, nocturia was not only affecting the older populations but also caused significant bothersome and negative impacts on QoL in younger males.

Author Contributions: Conceptualization, resources and data curation, J.W. Yuen and C.F. Ng; methodology and software, J.W.Yuen; software, X.X.; validation, J.W. Yuen, I.Y. Wong and C.F. Ng; formal analysis and supervision, J.W. Yuen and I.Y. Wong; investigation, X.X.; writing-original draft preparation, J.W. Yuen; writing - review and editing, J.W. Yuen, I.Y. Wong, P.K. Chiu, J.Y. Teoh, C. Chan, C. Yee, C.F. Ng; project administration, J.W. Yuen; funding acquisition, J.W. Yuen. All authors have read and agreed to the published version of the manuscript.

Funding: This research was funded by the Departmental Research Fund of the Hong Kong Polytechnic University, grant number P0008265.

Institutional Review Board Statement: The study was conducted according to the guidelines of the Declaration of Helsinki, and approved by the Institutional Review Board of the Hong Kong Polytechnic University (protocol code HSEARS2015085001-01; date of approval: 16-September-2015).

Informed Consent Statement: Informed consent was obtained from all subjects involved in the study.

Data Availability Statement: The raw data presented in this study are available on request from the corresponding author. The data are not publicly available due to research data governance policy of institution that has given ethical approval to this study.

Acknowledgments: The authors are grateful to Ms. Sara Fung and Mr. Chris Lam for their contributions in providing professional translation service. The authors would also like to thank Mr. jacky Ka-kit Tam, Ms. Hilary Hiu-yin Chung, Ms. Shermaine Cheuk-ying Ng, Mr. Toby Chung-wai Chau, Ms. Ka-wai Chan, Ms. Yuen-yi Cheung, Ms. Chui-yu Lau, Ms. Ying-kwan Lau, Ms. Wing-yee Lee, Ms. Iris Hing-yi Ma, Ms. Sau-wan Tang, Ms. Pui-yee Tam, Ms. Po-yan Lee, Ms. Cheuk-yan Leung, Ms. Chui-yan Lau, Mr. Cho-chak Lee, and Ms. Nathania Shing-yan Suen for their efforts in data collection and data entry.

Conflicts of Interest: The authors declare no conflict of interest.

\section{References}

1. van Kerrebroeck P; Abrams P; Chaikin D; Donovan J; Fonda D; Jackson S; Jennum P; Johnson T; Lose G; Mattiasson A; Robertson G; Weiss J. Standardisation Sub-committee of the International Continence Society. The standardisation of terminology in nocturia: report from the Standardisation Sub-committee of the International Continence Society. Neurourol Urodyn 2002, 21, 179-83. doi: 10.1002/nau.10053. PMID: 11857672.

2. Kobelt G; Borgström F; Mattiasson A. Productivity, vitality and utility in a group of healthy professionally active individuals with nocturia. BJU Int 2003, 91, 190-195. doi: 10.1046/j.1464-410x.2003.04062.x.

3. Hunter P. To sleep, perchance to live. Sleeping is vital for health, cognitive function, memory and long life. EMBO Rep 2008, 9 , 1070-3. doi: 10.1038/embor.2008.197.

4. Choi EPH; Wan EYF; Kwok JYY; Chin WY; Lam CLK. The mediating role of sleep quality in the association between nocturia and health-related quality of life. Health Qual Life Outcomes 2019, 17, 181. doi: 10.1186/s12955-019-1251-5.

5. Schneider T; de la Rosette JJ; Michel MC. Nocturia: a non-specific but important symptom of urological disease. Int J Uro/2009 16, 249-56. doi: 10.1111/j.1442-2042.2008.02246.x.

6. Gulur DM; Mevcha AM; Drake MJ. Nocturia as a manifestation of systemic disease. BJU Int 2011, 107, 702-713. doi: 10.1111/j.1464-410X.2010.09763.x.

7. Weiss JP; Blaivas JG; Jones M; Wang JT; Guan Z; 037 Study Group. Age related pathogenesis of nocturia in patients with overactive bladder. J Uro/2007, 178, 548-551. doi: 10.1016/j.juro.2007.03.117.

8. Homma Y. Classification of nocturia in the adult and elderly patient: a review of clinical criteria and selected literature. BJU Int 2005, 96, 8-14. doi: 10.1111/j.1464-410X.2005.05655.x. 
9. Ali A; Snape J. Nocturia in older people: a review of causes, consequences, assessment and management. Int J Clin Pract 2004, 58, 366-373. doi: 10.1111/j.1368-5031.2004.00086.x.

10. Van Kerrebroeck PE; Dmochowski R; FitzGerald MP; Hashim H; Norgaard JP; Robinson D; Weiss JP. Nocturia research: current status and future perspectives. Neurourol Urodyn 2010, 29, 623-628. doi: 10.1002/nau.20913.

11. Wyndaele JJ. Nocturia and quality of life. Eur Uro/2012, 61, 85-87. doi: 10.1016/j.eururo.2011.09.014.

12. Furtado D; Hachul H; Andersen ML; Castro RA; Girão MB; Tufik S. Nocturia × disturbed sleep: a review. Int Urogynecol J 2012, 23, 255-267. doi: 10.1007/s00192-011-1525-x.

13. Bosch JL; Weiss JP. The prevalence and causes of nocturia. J Uro/2010, 184, 440-446. doi: 10.1016/j.juro.2010.04.011.

14. Wang JY; Liao L; Liu M; Sumarsono B; Cong M. Epidemiology of lower urinary tract symptoms in a cross-sectional, populationbased study: The status in China. Medicine (Baltimore) 2018, 97, e11554. doi: 10.1097/MD.0000000000011554.

15. Li MK; Garcia LA; Rosen R. Lower urinary tract symptoms and male sexual dysfunction in Asia: a survey of ageing men from five Asian countries. BJU Int 2005, 96, 1339-1354. doi: 10.1111/j.1464-410X.2005.05831.x.

16. Yee $\mathrm{CH}$; Chan CK; Teoh JYC; Chiu PKF; Wong JHM; Chan ESY; Hou SSM; Ng CF. Survey on prevalence of lower urinary tract symptoms in an Asian population. Hong Kong Med J2019, 25, 13-20. doi: 10.12809/hkmj187502.

17. Ho LY; Chan CK; Chu PS. Patient opinion of lower urinary tract symptoms and their treatment: a cross-sectional survey in Hong Kong public urology clinics. Hong Kong Med J 2017, 23, 562-569. doi: 10.12809/hkmj166102.

18. Wong MKT; Leung SYL. Cross-sectional population based study on nocturia in Hong Kong: Prevalence, impacts, and treatment seeking behaviours. BJU Int 2016, 117, 11.

19. Tam PC. Nocturia survey in Hong Kong. HK Med D2005, 10, 13.

20. Chiu MYL; Wong HT; Yang X. Distress Due to Urinary Problems and Psychosocial Correlates among Retired Men in Hong Kong. Int J Environ Res Public Health 2020, 17, 2533. doi: 10.3390/ijerph17072533.

21. Census \& Statistics Department. Hong Kong Population by-census, 2017. Available online: https:www.censtatd.gov.hk/hkstat/sub/sp459.jsp?productCode=B112160A (Accessed on 4 August 2021).

22. Abraham L; Hareendran A; Mills IW; Martin ML; Abrams P; Drake MJ; MacDonagh RP; Noble JG. Development and validation of a quality-of-life measure for men with nocturia. Uro/ 2004, 63, 481-486. doi: 10.1016/j.urology.2003.10.019.

23. Irwin DE; Milsom I; Hunskaar S; Reilly K; Kopp Z; Herschorn S; Coyne K; Kelleher C; Hampel C; Artibani W; Abrams P. Populationbased survey of urinary incontinence, overactive bladder, and other lower urinary tract symptoms in five countries: results of the EPIC study. Eur Uro/2006, 50, 1306-1314. doi: 10.1016/j.eururo.2006.09.019.

24. Kageyama T; Kabuto M; Nitta H; Kurokawa Y; Taira K; Suzuki S; Takemoto T. Prevalence of nocturia among Japanese adults. Psychiatry Clin Neurosci 2000, 54, 299-300. doi: 10.1046/j.1440-1819.2000.00686.x.

25. Liew LC; Tiong HY; Wong ML; Png DC; Tan JK. A population study of nocturia in Singapore. BJU Int 2006, 97, 109-112. doi: 10.1111/j.1464-410X.2006.05867.x.

26. Wang $Y_{;}$Hu H; Xu K; Zhang $X ;$ Wang $X ; N a$ Y; Kang X. Prevalence, risk factors, and symptom bother of nocturia: a populationbased survey in China. World J Uro/2015, 33, 677-683. doi: 10.1007/s00345-014-1411-5.

27. Kalejaiye O; Persad R; Rees J. Assessment of lower urinary tract symptoms in younger men. Br J Fam Med 2013, 1, 24-27.

28. Jeong SJ; Yeon JS; Lee JK; Jeong JW; Lee BK; Park YH; Lee SC;I Jeong CW; Kim JH; Hong SK; Byun SS; Lee SE. Chronic lower urinary tract symptoms in young men without symptoms of chronic prostatitis: urodynamic analyses in 308 men aged 50 years or younger. Korean J Uro/2014, 55, 341-348. doi: 10.4111/kju.2014.55.5.341.

29. Chang SC; Lin AT; Chen KK; Chang LS. Multifactorial nature of male nocturia. Urol, 2006, 67, 541-544. doi: 10.1016/j.urology.2005.09.037.

30. Asplund R. Nocturia: consequences for sleep and daytime activities and associated risks. Eur Uro/ Supp/2005, 3, $24-32$.

31. Kupelian V; Wei JT; O'Leary MP; Norgaard JP; Rosen RC; McKinlay JB. Nocturia and quality of life: results from the Boston area community health survey. Eur Uro/2012, 61, 78-84. doi: 10.1016/j.eururo.2011.05.065. 